\title{
PENGARUH MARKETING MIX TERHADAP KEPUTUSAN PEMBELIAN PARFUM DI AZZWARS PARFUM LUBEG PADANG
}

\author{
Alfanda Andika, Febsri Susanti \\ Sekolah Tinggi Ilmu Ekonomi KBP Padang \\ febsrisusanti@akbpstie.ac.id
}

\begin{abstract}
Influence of Marketing Mix Buying Decision Against Perfume at Perfume Azzwars Lubeg Padang". Research was conducted on Azzwars Perfume Lubeg Padang. The purpose of this study were: 1) to analyze the influence of the effect of variable products, the purchase decision perfume in Azzwars Perfume Lubeg Padang, 2) to analyze the influence of variables influence the price, the purchase decision perfume in Azzwars Perfume Lubeg Padang, 3) to analyze the influence of variables influence the place, Decision to purchase perfume at Azzwars perfume Lubeg Padang, 4) to analyze the influence of variables sale, the purchase decision perfume fragrances Azzwars Lubeg Padang. This type of research is qualitative research. The object of this study is Azzwars Perfume Lubeg Padang. Data analysis method used is descriptive analysis and multiple linear regression analysis. Based on the research results obtained the following conclusions: 1) The product does not significantly influence the purchase decision of consumers Azzwars Perfume Lubeg Padang. 2) The price does not significantly influence the purchase decision of consumers Azzwars Perfume Lubeg Padang, 3) place significant effect on the purchase decision of consumers Azzwars Perfume Lubeg Padang, 4) Promotion does not significantly influence the purchase decision of consumers Azzwars Perfume Lubeg Padang, 5) Marketing Mix effect positive and significant impact on consumer purchase decision Azzwars Perfume Lubeg Padang.
\end{abstract}

Keywords: Product, Price, Place, Promotion, Marketing Mix, Purchase Decision.

\section{PENDAHULUAN}

Parfum adalah produk yang
sudah tidak asing lagi dalam
kehidupan sehari-hari. Apalagi saat ini
aroma parfum yang ditawarkan sudah
semakin beragam, baik yang
dikhususkan untuk pria, wanita,
ataupun untuk keduanya. Kata parfum

sendiri berasal dari bahasa latin "per fumum" yang berarti melalui asap. Riwayat parfum telah ada sejak zaman Mesopotamia kuno sekitar lebih dari 4000 tahun yang lalu.

Pada zaman dahulu, orang-orang menggunakan tanaman herbal, 
rempah-rempah dan bunga dan dicampurkan bersama untuk membuat wewangian. Selanjutnya pada pertengahan abad ke-15 parfum mulai dicampur minyak dan alkohol. Meskipun demikian, parfum baru mengalami kemajuan pesat pada abad ke-18 dengan munculnya beragam aroma wewangian dan botol yang indah (Wikipedia, 2011). Dalam 20 tahun terakhir ini terdapat peningkatan yang pesat pada jumlah produksi parfum (Albano, Goodelman, Kunes, \& O'Rourke 2010).

Bahkan industri parfum diperkirakan dapat memperoleh hasil penjualan tahunan sebesar 25-30 juta dollar (NYtimes, 2009). Hal tersebut menunjukkan adanya kebutuhan masyarakat akan parfum yang semakin hari semakin meningkat. Ada beberapa alasan mengapa konsumen menggunakan parfum. Dari hasil penelitian Borgave \& Chaudari (2010), konsumen merasa lebih baik dan merasa lebih percaya diri setelah menggunakan parfum. Hasil penelitian lainnya dari Borgave \& Chaudari (2010), adalah konsumen menilai wangi parfum berada di urutan pertama yang dipertimbangkan pada saat akan membeli parfum. Urutan selanjutnya adalah merek, harga, dan kemasan parfum itu sendiri.

Perilaku membeli merupakan salah satu contoh dari perilaku yang tampak (overt behavior). Faktor penentu dari perilaku yang tampak adalah besarnya intensi untuk menampilkan atau tidak menampilkan perilaku tersebut (Ajzen, 2005). Menurut Schiffman (dalam Barata, 2007), intensi adalah hal yang berkaitan dengan kecenderungan seseorang untuk melakukan suatu tindakan atau perilaku tertentu. Ajzen (2005) mengemukakan bahwa intensi terdiri dari tiga aspek yaitu sikap terhadap perilaku, norma subjektif, dan kontrol terhadap perilaku.

Menurut Kotler (2012) secara umum bauran pemasaran menekankan pada pengertian suatu strategi yang mengintegrasikan Product, Price, Promotion dan Place dimana kesemuanya itu diarahkan untuk dapat menghasilkan omset penjualan yang maksimal atas produk yang dipasarkan dengan memberikan kepuasan pada para pelanggan.

Menurut Stanton (1996) bahwa pemasaran dapat diartikan sebagai suatu system keseluruhan dari kegiatan bisnis ang ditujukan untuk merencanakan, menentukan harga, mempromosikan dan mendistribusikan barang serta jasa yang memuaskan kebutuhan konsumen.

Kepuasan pelanggan yang dimaksud yaitu kepuasan terhadap Product, kepuasan terhadap Price, kepuasan terhadap Promotion dan kepuasan terhadap Place dari pembelian parfum. Hal yang terjadi sekarang adalah ada perbedaan antara harapan dan persepsi konsumen. Harapan konsumen cenderung lebih besar daripada nilai yang dierima oleh konsumen. Hal ini jika terjadi terus menerus akan membuat konsumen lari ke produk pesaing. Sehingga hal ini perlu diperhatikan secara sungguhsungguh oleh perusahaan.

\section{LANDASAN TEORI}

Menurut Kotler (2001: 7) pemasaran adalah suatu proses sosial dan manajerial yang membuat individu dan kelompok memperoleh apa yang mereka butuhkan dan inginkan lewat 
penciptaan dan pertukaran timbal balik produk dan nilai dengan orang lain.

Pemasaran menurut Kartajaya (2006: xxvi) adalah sebuah disiplin ilmu bisnis strategis yang mengarahkan proses penciptaan, penawaran dan perubahan value dari suatu inisiator kepada stakeholder-nya yang dalam keseluruhan prosesnya sesuai dengan akad dan prinsipprinsip muamalah (bisnis) dalam islam.

Kotler dan Amstrong (2001: 23) mendefinisikan konsep pemasaran adalah falsafah manajemen pemasaran yang berkeyakinan bahwa pencapaian sasaran organisasi tergantung pada penentuan kebutuhan dan keinginan pasar sasaran dan penyampaian kepuasan yang didambakan itu lebih efektif dan efisien daripada yang dilakukan pesaing.

Pengertian Manajemen Pemasaran Menurut Para Ahli Manajemen Marketing Dalam dunia usaha yang semakin bersaing, tantangan yang dihadapi para produsen barang akan semakin berat dalam usahanya untuk memasukkan barangnya ke arena pertukaran. Segala usaha di bidang pemasaran (marketing) harus ditempuh sehingga penggarapan secara sungguh-sungguh agar tidak terlempar ke luar "percaturan" akibat semakin banyaknya orang yang sama dalam bidang yang telah digarap.

Dalam persaingan yang semakin ketat, kegiatan peningkatan produksi tidak lagi dipandang sebagai masalah yang berat dibandingkan dengan kegiatan memasarkan barang yang dihasilkannya. Dengan demikian dapat dikatakan bahwa keberhasilan dalam memasarkan merupakan kunci keberhasilan dari suatu perusahaan.

Kegiatan pemasaran memiliki nilai positif baik dilihat dari sisi konsumen maupun dari sisi produsen. Dari sisi konsumen, pemasaran dipandang sebagai kegiatan yang dapat menawarkan berbagai alternatif alat pemuas kebutuhan, sehingga nilai kepuasan itu sendiri bertambah besar. Dari sisi produsen, pemasaran sebagai kegiatan untuk lebih meningkatkan pelayanan pemenuhan kebutuhan konsumen. Oleh karena itu, pemasaran sesungguhnya bukan sematamata berkaitan dengan kepentingan produsen saja melainkan juga kepentingan konsumen.

Pemasaran merupakan salah satu dari kegiatan-kegiatan pokok yang dilakukan oleh perusahaan untuk mempertahankan kelangsungan hidup, untuk berkembang, dan mendapatkan laba. Arti pemasaran biasanya sering disalah artikan dengan pengertian penjualan, perdagangan dan distribusi. Padahal istilah-istilah tersebut hanya merupakan satu bagian dari aktivitas pemasaran secara keseluruhan. Proses pemasaran dimulai jauh sebelum barang diproduksi dan tidak berakhir dengan penjualan tetapi bagaimana dapat memberikan kepuasan kepada konsumen.

Sehingga sejak orang mengenal kegiatan pemasaran, telah banyak definisi-definisi pemasaran yang dikemukakan. Definisi tersebut awalnya menitikberatkan pada barang, kemudian pada lembaga-lembaga yang diperlukan untuk melaksanakan proses penjualan, dan pada fungsi-fungsi yang dijalankan untuk memungkinkan dilakukannya transaksi pemasaran. Manajemen pemasaran adalah 
penganalisaan,

perencanaan,

pelaksanaan, dan pengawasan program-program yang bertujuan menimbulkan pertukaran dengan pasar yang dituju dengan maksud untuk mencapai tujuan perusahaan.

Titik berat diletakkan pada penawaran perusahaan dalam memenuhi kebutuhan dan keinginan pasar tersebut serta menentukan harga, mengadakan komunikasi, dan distribusi yang efektif untuk memberitahu, mendorong, serta melayani pasar. Jadi, manajemen pemasaran dirumuskan sebagai suatu proses manajemen yang meliputi penganalisaan, perencanaan, pelaksanaan, dan pengawasan kegiatan pemasaran yang dilakukan oleh perusahaan.

Kegiatan ini bertujuan menimbulkan pertukaran yang diinginkan, baik yang menyangkut barang dan jasa, atau benda-benda lain yang dapat memenuhi kebutuhan psikologis, sosial dan kebudayaan. Proses pertukaran dapat ditimbulkan baik oleh penjual, maupun pembeli yang menguntungkan kedua belah pihak. Penentuan produk, harga, promosi dan tempat untuk mencapai tanggapan yang efektif disesuaikan dengan sikap dari perilaku konsumen, dan sebaliknya sikap dan perilaku konsumen dipengaruhi sedemikian rupa sehingga menjadi sesuai dengan produk yang ditawarkan perusahaan.

Menurut Payne (2000: 155) bauran pemasaran untuk jasa adalah 4P, yaitu product, price, place, dan promotion customer service (produk, harga, tempat, dan promosi).

Setelah evaluasi alternatif, menurut Kotler (2012: 174), konsumen mungkin akan membentuk niat untuk membeli produk atau jasa yang paling disukai namun sebelum melakukan keputusan pembelian, ada dua faktor yang berada diantara niat pembelian dan keputusan pembelian yaitu pendirian orang lain yaitu berdasar pengaruh orang lain sedangkan faktor yang kedua adalah faktor situasi yang tidak diantisipasi. Faktor yang kedua ini dapat muncul dan mengubah niat pembelian. Dalam menjalankan niat pembelian, konsumen dapat membuat lima sub-keputusan pembelian yaitu keputusan atas merek, keputusan pemasok, keputusan kuantitas, keputusan waktu, dan keputusan metode pembayaran.

Endri Wahyudi Januaristo (2005: xv), analisis bauran pemasaran jasa yang mempengaruhi konsumen dalam memilih perusahaan jasa tranportasi bis malam antar kota antar propinsi (studi kasus pada mahasiswa Fakultas Ekonomi Universitas Brawijaya Malang). Dengan menggunakan alat analisis regresi linier berganda, variabel bauran pemasaran jasa sebagai variabel bebas. Sedangkan variabel terikatnya adalah keputusan konsumen dalam memilih perusahaan jasa transportasi bis malam antar kota antar propinsi.

Jenis penelitian ini adalah penelitian survey yang bersifat menjelaskan. Populasi dalam penelitian ini adalah mahasiswa Fakultas Ekonomi Universitas Brawijaya sejumlah 3236, sedangkan sampel yang diambil sejumlah 100 mahasiswa. Berdasarkan hasil perhitungan regresi linier berganda, diketahui bahwa secara simultan 
$\begin{array}{lrr}\text { variabel } & \text { bauran } & \text { pemasaran } \\ \text { berpengaruh } & \text { signifikan } & \text { dalam }\end{array}$ pemilihan perusahaan jasa transportasi bis malam antar kota antar propinsi. Sedangkan secara parsial hanya produk, harga, promosi dan orang yang berpengaruh secara signifikan. Variabel produk yang mempunyai pengaruh dominan dalam pemilihan perusahaan jasa transportasi bis malam antar kota antar propinsi. Daniel Meihanto (2007: xviii), analisis pengaruh bauran pemasaran terhadap keputusan konsumen dalam memilih hotel (studi pada Hotel Asida Batu).

Dari hasil analisis regresi linier berganda, dinyatakan bahwa seluruh variabel bauran pemasaran yang ada, secara simultan berpengaruh secara signifikan terhadap keputusan konsumen memilih hotel Asida Batu dan secara parsial variabel produk, promosi, dan bukti fisik tidak berpengaruh secara signifikan terhadap keputusan konsumen memilih hotel Asida Batu. Sedangkan variabel harga merupakan variabel yang dominan terhadap keputusan konsumen emilih hotel Asida Batu.

\section{METODE PENELITIAN}

Jenis penelitian ini adalah kuantitatif yaitu penelitian yang menekankan pada pengujian teori-teori melalui pengukuran variabel variabel penelitian dengan angka dan melakukan analisis data dengan prosedur statistik (Indriantoro, 2005 : 12). Pendekatan yang digunakan dalam penelitian ini adalah pendekatan survei yaitu penelitian yang mengambil sampel dari satu populasi dan menggunakan kuesioner sebagai alat pengumpulan data yang pokok (Singarimbun, 1995 : 3).

Penelitian ini akan dilaksanakan di Azzwars Parfum Lubeg Padang dengan mengumpulkan data - data penelitian dar jawaban responden penelitian.

Teknik pengambilan sampel dalam penelitian ini adalah Sampel Acak Sederhana (Simple Random Sampling). Sampel Acak Sederhana (Simple Random Sampling) ialah sebuah sampel yang diambil sedemikian rupa sehingga tiap unit penelitian atau satuan elementer dari populasi mempunyai kesempatan yang sama untuk dipilih sebagai sampel (Singarimbun, 1995: 154).

Data primer merupakan sumber data penelitian yang diperoleh secara langsung dari sumber asli (tidak melalui media perantara) (Indriantoro, 1999: 146). Dalam penelitian ini data diperoleh dari kuesioner responden tentang beberapa variabel yang diteliti.

Data sekunder merupakan sumber data penelitian yang diperoleh peneliti secara tidak langsung melalui media perantara (diperoleh dan dicatat oleh pihak lain) (Indriantoro, 1999: 147). Data sekunder yangdigunakan dalam penelitian ini seperti: mengambil dan mengolah data yang sudah ada, yakni dokumen-dokumen yang dimiliki oleh organisasi seperti halnya struktur organisasi, selain itu data sekunder dapat diperoleh dari brosur, internet, majalah yang berkaitan dengan konsumen Azzwars Parfum Lubeg Padang. Data ini digunakan mendukung data primer. 
Dokumentasi adalah mencari data mengenai hal-hal atau variabel yang berupa catatan, transkip, buku, surat kabar, majalah, prasasti, notulen rapat, lengger, agenda dan sebagainya (Arikunto, 2002: 231). Dalam penelitian ini dilakukan dengan melihat majalah, brosur dan internet yang berhubungan dengan persepsi untuk memperoleh landasan teori dan mendapatkan data yang dapat menunjang penelitian.

Selanjutnya agar jawaban responden dapat diukur maka jawaban responden diberi skor. Dalam pemberian skor maka digunakan skala Likert menurut (Singarimbun, 1995: 111) adalah "skala likert merupakan cara pengukuran yang berhubungan dengan pertanyaan tentang sikap seseorang (responden) terhadap sesuatu".

Selanjutnya dalam prosedur skala Likert ini adalah menentukan skor atas setiap pertanyaan dalam kuesioner yang disebarkan. Jawaban dari responden dibagi dalam lima kategori penilaian dimana masingmasing pertanyaan diberi skor satu sampai lima. Dalam penelitian ini terdiri lima jawaban yang mengandung variasi nilai bertingkat, antara lain: sangat setuju dengan nilai 5 , setuju dengan nilai 4 , ragu-ragu dengan nilai 3 , tidak setuju dengan nilai 2 , dan sangat tidak setuju dengan nilai 1 (Singarimbun, 1995: 111).

Untuk mendapatkan nilai pemeriksa yang tidak bias dan efisien (Best Linear Unbias Estimator/BLUE) dari suatu persamaan regresi linier berganda dengan metode kuadrat terkecil (least Squares), perlu dilakukan 50 pengujian dengan jalan memenuhi persyaratan asumsi klasik.

\section{HASIL DAN PEMBAHASAN}

Azzwar Parfum didirikan oleh seorang wirausaha bernama Alkausar yang merintis bersama 3 orang saudaranya yang bermula dari warung kelontong orang tua mereka yang menyajikan kebutuhan sehari - hari, termasuk kosmetik, sandal dan lain lain. Modal awalnya adalah $\mathrm{Rp}$ 5.000.000,00. Seiring perjalanan waktu, ternyata usaha parfum yang tadinya hanya menjual sebagai usaha sampingan justru berkembang baik. Dalam tempo 3 tahun, omset parfum yang dijual melebihi pemasukan warung kelontong yang dimiliki oleh orang tua mereka.

Melihat peluang yang begitu besar pada pertengahan tahun 2003 Alkausar bersama saudaranya mulai membuka produk parfum secara khusus. Saat itu, mereka hanya murni berjualan parfum artinya perusahaan mereka diawali dari perusahaan distributor atau perusahaan dagang. Lambat laun terfikirkan oleh pemilik untuk meracik bahan parfum sendiri. Berbagai inovasi dilakukan dengan mengeluarkan berbagai produk.

Memasuki tahun 2006, setelah membuka sejumlah outlet mereka membangun grosir dan mitra usaha. Pihak - pihak yang tertarik membuka usaha dapat melakukan Franchise dengan membeli barang senilai Rp 15.000.000,00. Pada tahun 2007 ekspansi dilakukan dengan berbagai promosi dan iklan diradio. Usaha mereka terus berkembang dan outlet Azzwars mencapai 45 outlet yang tersebar di kota Padang dan kota kota lain di Sumatera Barat. Untuk outlet yang berada di Kota Padang berdiri pada tahun 2008 dengan pemilik bernama Yudha Anggara yang 
melakukan kerjasama dengan membeli

frenchise produk Azzwars Parfum.

Tabel 1

Hasil Uji Validitas Variabel Produk

Item-Total Statistics

\begin{tabular}{|l|r|r|r|r|r|}
\hline & $\begin{array}{c}\text { Scale Mean if } \\
\text { Item Deleted }\end{array}$ & $\begin{array}{c}\text { Scale } \\
\text { Variance if } \\
\text { Item Deleted }\end{array}$ & $\begin{array}{c}\text { Corrected } \\
\text { Item-Total } \\
\text { Correlation }\end{array}$ & $\begin{array}{c}\text { Squared } \\
\text { Multiple } \\
\text { Correlation }\end{array}$ & $\begin{array}{c}\text { Cronbach's } \\
\text { Alpha if Item } \\
\text { Deleted }\end{array}$ \\
\hline P1 & 16,02 & 3,939 &, 377 &, 216 &, 683 \\
P2 & 16,28 & 4,082 &, 536 &, 308 &, 622 \\
P3 & 16,22 & 3,729 &, 420 &, 218 &, 667 \\
P4 & 16,04 & 4,160 &, 456 &, 301 &, 648 \\
P5 & 16,08 & 3,751 &, 517 &, 620 \\
\hline
\end{tabular}

Sumber : Data primer yang diolah, 2016

Tabel 2

Hasil Uji Validitas Variabel Harga Item-Total Statistics

\begin{tabular}{|l|r|r|r|r|r|}
\hline & $\begin{array}{c}\text { Scale Mean if } \\
\text { Item Deleted }\end{array}$ & $\begin{array}{c}\text { Scale } \\
\text { Variance if } \\
\text { Item Deleted }\end{array}$ & $\begin{array}{c}\text { Corrected } \\
\text { Item-Total } \\
\text { Correlation }\end{array}$ & $\begin{array}{c}\text { Squared } \\
\text { Multiple } \\
\text { Correlation }\end{array}$ & $\begin{array}{r}\text { Cronbach's } \\
\text { Alpha if Item } \\
\text { Deleted }\end{array}$ \\
\hline P1 & 15,48 & 6,636 &, 329 &, 149 &, 710 \\
P2 & 15,88 & 6,086 &, 586 &, 365 &, 626 \\
P3 & 15,58 & 5,741 &, 538 &, 294 &, 632 \\
P4 & 15,68 & 6,078 &, 453 &, 269 &, 666 \\
P5 & 15,86 & 4,849 &, 490 &, 665 \\
\hline
\end{tabular}

Sumber : Data primer yang diolah, 2016

Tabel 3

Hasil Uji Validitas Variabel Tempat Item-Total Statistics

\begin{tabular}{|l|r|r|r|r|r|}
\hline & $\begin{array}{c}\text { Scale Mean if } \\
\text { Item Deleted }\end{array}$ & $\begin{array}{c}\text { Scale } \\
\text { Variance if } \\
\text { Item Deleted }\end{array}$ & $\begin{array}{c}\text { Corrected } \\
\text { Item-Total } \\
\text { Correlation }\end{array}$ & $\begin{array}{c}\text { Squared } \\
\text { Multiple } \\
\text { Correlation }\end{array}$ & $\begin{array}{c}\text { Cronbach's } \\
\text { Alpha if Item } \\
\text { Deleted }\end{array}$ \\
\hline P1 & 16,70 & 3,646 &, 403 &, 261 &, 587 \\
P2 & 16,66 & 4,025 &, 444 &, 304 &, 575 \\
P3 & 16,46 & 3,806 &, 340 &, 141 &, 619 \\
P4 & 16,48 & 3,565 &, 502 &, 266 &, 537 \\
P5 & 16,66 & 3,944 &, 318 &, 165 &, 628 \\
\hline
\end{tabular}

Sumber : Data primer yang diolah, 2016 


\section{Tabel 4}

\section{Hasil Uji Validitas Variabel Promosi Item-Total Statistics}

\begin{tabular}{|l|r|r|r|r|r|}
\hline & $\begin{array}{c}\text { Scale Mean if } \\
\text { Item Deleted }\end{array}$ & $\begin{array}{c}\text { Scale } \\
\text { Variance if } \\
\text { Item Deleted }\end{array}$ & $\begin{array}{c}\text { Corrected } \\
\text { Item-Total } \\
\text { Correlation }\end{array}$ & $\begin{array}{c}\text { Squared } \\
\text { Multiple } \\
\text { Correlation }\end{array}$ & $\begin{array}{c}\text { Cronbach's } \\
\text { Alpha if Item } \\
\text { Deleted }\end{array}$ \\
\hline P1 & 15,80 & 5,859 &, 504 &, 318 &, 674 \\
P2 & 15,54 & 5,019 &, 609 &, 388 &, 625 \\
P3 & 15,64 & 6,213 &, 329 &, 161 &, 730 \\
P4 & 15,86 & 3,920 &, 629 &, 487 &, 620 \\
P5 & 15,48 & 6,232 &, 410 &, 240 &, 705 \\
\hline
\end{tabular}

Sumber : Data primer yang diolah, 2016

\section{Tabel 5}

Hasil Uji Validitas Variabel Keputusan Pembelian Item-Total Statistics

\begin{tabular}{|l|r|r|r|r|r|}
\hline & $\begin{array}{c}\text { Scale Mean if } \\
\text { Item Deleted }\end{array}$ & $\begin{array}{c}\text { Scale } \\
\text { Variance if } \\
\text { Item Deleted }\end{array}$ & $\begin{array}{c}\text { Corrected } \\
\text { Item-Total } \\
\text { Correlation }\end{array}$ & $\begin{array}{c}\text { Squared } \\
\text { Multiple } \\
\text { Correlation }\end{array}$ & $\begin{array}{c}\text { Cronbach's } \\
\text { Alpha if Item } \\
\text { Deleted }\end{array}$ \\
\hline P1 & 16,90 & 3,566 &, 592 &, 423 &, 540 \\
P2 & 17,02 & 4,060 &, 354 &, 281 &, 653 \\
P3 & 16,74 & 4,154 &, 363 &, 200 &, 647 \\
P4 & 16,80 & 4,162 &, 416 &, 213 &, 624 \\
P5 & 16,54 & 3,928 &, 411 &, 241 &, 626 \\
\hline
\end{tabular}

Sumber : Data primer yang diolah, 2016

\section{Tabel 6}

Hasil Uji Reliabilitas

\begin{tabular}{|c|l|l|l|}
\hline No & \multicolumn{1}{|c|}{ Variabel } & Cronbach's Alpha & Keterangan \\
\hline $\mathbf{1}$ & Produk & 0,697 & Reliabel \\
\hline $\mathbf{2}$ & Harga & 0,709 & Reliabel \\
\hline $\mathbf{3}$ & Tempat & 0,643 & Reliabel \\
\hline $\mathbf{4}$ & Promosi & 0,724 & Reliabel \\
\hline $\mathbf{5}$ & Keputusan Pembelian & 0,671 & Reliabel \\
\hline
\end{tabular}

Sumber : Data primer yang diolah, 2016 
Tabel 7

Hasil Analisis Regresi Linier Berganda

Coefficients(a)

\begin{tabular}{|c|c|c|c|c|c|c|c|c|}
\hline \multirow{2}{*}{\multicolumn{2}{|c|}{ Model }} & \multicolumn{2}{|c|}{$\begin{array}{l}\text { Unstandardized } \\
\text { Coefficients }\end{array}$} & \multirow{2}{*}{$\begin{array}{c}\text { Standardized } \\
\text { Coefficients } \\
\text { Beta }\end{array}$} & \multirow[b]{2}{*}{$t$} & \multirow[b]{2}{*}{ Sig. } & \multicolumn{2}{|c|}{$\begin{array}{l}\text { Collinearity } \\
\text { Statistics }\end{array}$} \\
\hline & & $B$ & Std. Error & & & & Tolerance & VIF \\
\hline \multirow[t]{5}{*}{1} & (Constant) & 8,594 & 3,342 & & 2,571 &, 012 & & \\
\hline & Produk & ,004 & ,143 & ,004 & ,026 & 979 & ,369 & 2,712 \\
\hline & Harga &,- 014 & ,117 &,- 018 &,- 122 & ,903 & ,367 & 2,722 \\
\hline & Tempat & ,538 & ,089 & ,524 & 6,031 & ,000 & 994 & 1,006 \\
\hline & Promosi & ,074 & ,078 & ,088 & 959 & ,340 & 897 & 1,115 \\
\hline
\end{tabular}

a Dependent Variable: Keputusan

Sumber: Data primer yang diolah, 2016

Pengujian ini bertujuan untuk mengetahui hubungan signifikan dari masing-masing variabel independen terhadap variabel dependen. Uji t dilakukan untuk memeriksa lebih lanjut manakah diantara keempat variabel independen dari Marketing Mix tersebut signifikan atau tidak terhadap keputusan pembelian yang dikemukakan pada tabel 4.19

Dari tabel 4.19 diketahui diperoleh nilai thitung untuk variabel produk sebesar 0,026 dengan signifikansi 0,979 . Nilai Sig. variabel produk (X1) sebesar $0,979>0,05=\mathrm{a}$ maka H1 ditolak, berarti tidak terdapat pengaruh yang signifikan antara variabel produk(X1) terhadap keputusan pembelian (Y) di Azzwars Parfum Lubeg Padang. Hal ini disebabkan karena variabel produk yang ditawarkan Azzwars Parfum Lubeg Padang tidak terlalu menarik perhatian pembeli karena banyaknya kompetitor yang menjual produk parfum.

Untuk variabel harga terdapat nilai thitung sebesar $-0,122$ dengan signifikansi variabel harga(X2) sebesar 0,903> 0,05 maka H2 ditolak, berarti tidak terdapat pengaruh yang signifikan antara variabel harga (X2) terhadap keputusan pembelian (Y) di Azzwars Parfum Lubeg Padang. Hal ini disebabkan karena responden merasa harga parfum yang ditawarkan oleh Azzwars Parfum Lubeg Padang dirasakan tak sesuai dengan kualitas produk.

Untuk variabel tempat (X3) terdapat nilai thitung sebesar 6,031 dengan signifikansi variabel daya tanggap sebesar 0,000 $<0,05$ maka $\mathbf{H 3}$ diterima, berarti terdapat pengaruh yang signifikan antara variabel tempat terhadap keputusan pembelian (Y) di Azzwars Parfum Lubeg Padang. Hal ini disebabkan karena tempat penjualan Azzwars Parfum Lubeg Padang berada ditengah keramaian dan sangat strategis sehingga pembeli dapat melakukan pembelian disekitar lubeg.

Untuk variabel Promosi (X4) terdapat nilai thitung sebesar 0,959 dengan signifikansi variabel jaminan sebesar 0,349>0,05 maka H4 ditolak, berarti tidak terdapat pengaruh yang signifikan antara variabel promosi terhadap keputusan pembelian $(\mathrm{Y})$ di 
Azzwars Parfum Lubeg Padang. Hal ini disebabkan karena Azzwars Parfum Lubeg Padang tidak melakukan promosi secara langsung produk produk yang ditawarkan namun hanya melalui word of mouth.

\section{Tabel 8}

Hasil Uji F

ANOVA(b)

\begin{tabular}{|ll|r|r|r|r|l|}
\hline Model & & \multicolumn{1}{c|}{$\begin{array}{c}\text { Sum of } \\
\text { Squares }\end{array}$} & Df & Mean Square & F & Sig. \\
\hline 1 & Regression & 163,035 & 4 & 40,759 & 9,562 &, $000(\mathrm{a})$ \\
& Residual & 404,965 & 95 & 4,263 & & \\
& Total & 568,000 & 99 & & & \\
\hline
\end{tabular}

a Predictors: (Constant), Promosi, Tempat, Produk, Harga

b Dependent Variable: Keputusan

Sumber: Data Primer yang diolah, 2016

Berdasarkan hasil penelitian yang diperoleh setelah dilakukan pengujian terhadap 100 orang responden yang merupakan pembeli atau pelanggan dari Azzwar Parfum Lubeg padang maka dapat disimpulkan bahwa Marketing Mix berpengaruh signifikan terhadap keputusan pembelian parfum di Azzwar Parfum Lubeg Padang karena memiliki $\mathrm{F}$ - hitung > dari $\mathrm{F}$ tabel yaitu sebesar 9,562. Hal ini membuktikan bahwa bauran pemasaran mempengaruhi keputusan pembelian produk parfum di Azzwar Parfum.

Hasil penelitian ini sejalan dengan penelitian januaristo (2005) yang menemukan hasil bahwa secara simultan variabel bauran pemasaran berpengaruh signifikan dalam pemilihan perusahaan jasa transportasi bis malam antar kota antar propinsi. Hasil penelitian ini menunjukkan bahwa responden dominan menggunakan transportasi bus malam dengan bauran pemasaran yang mempengaruhi keputusan mahasiswa untuk menggunakan transportasi bus malam.
Hasil pengujian hipotesis secara parsial menunjukkan bahwa hanya variabel tempat yang berpengaruh signifikan terhadap keputusan pembelian hal ini terjadi karena jawaban konsumen atau pelanggan Azzwar Parfum lubeg padang yang cendrung melakukan pembelian karena tempat atau lingkungan Azzwar Parfum yang strategis. Sedangkan variabel harga, promosi dan produk tidak memiliki pengaruh terhadap keputusan pembelian parfum di Azzwar Parfum Lubeg Padang. Hal ini terjadi karena masyarakat atau lingkungan sekitar tidak didorong karena penetapan harga, promosi serta produk yang ada di Azzwar Parfum.

\section{Kesimpulan}

Berdasarkan hasil penelitian yang diperoleh pada bab sebelumnya dapat disimpulkan bahwa:

1. Objek penelitian adalah Azzwars Parfum Lubeg Padang.

2. Metode penelitian menggunakan analisis deskriptif dan regresi linier 
berganda dengan program aplikasi SPSS.

3. Variabel penelitian yang digunakan adalah Produk (X1), Harga (X2), Tempat (X2), Promosi (X2) dan Keputusan Pembelian konsumen Azzwars Parfum Lubeg Padang.

4. Produk tidak berpengaruh signifikan terhadap Keputusan Pembelian konsumen Azzwars Parfum Lubeg Padang.

5. Harga tidak berpengaruh signifikan terhadap Keputusan Pembelian konsumen Azzwars Parfum Lubeg Padang.

6. Tempat berpengaruh signifikan terhadap Keputusan Pembelian konsumen Azzwars Parfum Lubeg Padang.

7. Promosi tidak berpengaruh signifikan terhadap Keputusan Pembelian konsumen Azzwars Parfum Lubeg Padang.

8. Marketing Mix berpengaruh positif dan signifikan terhadap Keputusan Pembelian konsumen Azzwars Parfum Lubeg Padang.

\section{Saran}

Berdasarkan kepada keterbatasan penelitian yang telah dilakukan maka diajukan beberapa saran yang dapat memberikan manfaat positif antaralain sebagai berikut:

1. Pemilik Azzwars Parfum Lubeg Padang sebaiknya melakukan evaluasi harga produk parfum yang ditawarkan oleh pasar agar dapat meningkatkan persaingan harga dengan produk parfum lainnya.
2. Pemilik Azzwars Parfum Lubeg Padang sebaiknya melakukan promosi yang gencat ke daerah - derah terdekat dengan memasang iklan atau melakukan penyebaran brosur produk yang ditawarkan agar konsumen dapat mempertimbangkan untuk melakukan pembelian ke Azzwars Parfum Lubeg Padang.

3. Pemilik sebaiknya tetap mempertahankan kualitas produk yang dipasakan serta menciptakan suasana toko (Store Atmosphere) yang nyaman serta dapat menjadi daya tarik konsumen untuk melakukan pembelian parfum di Azzwars Parfum Lubeg Padang.

\section{DAFTAR PUSTAKA}

Atmodjo. $\quad$ Soekidjo. 2007. Pengembangan Sumber Daya Manusia, Cetakan Ke-2, Penerbit Reneka Cipta, Jakarta.

Dajan, Anto, 1996. Pengantar Metode Statistik. LP3S, Jakarta.

Engel, J.F. et al. 1994. Perilaku Konsumen. Jilid I. Alih bahasa: Agus Maulana. Jakarta: Erlangga.

Ghozali, Imam, 2005. Analisis Multivariate Dengan Program SPSS, Badan penerbit Universitas Diponegoro, Semarang.

Hidayati, R. R., \& Marlius, D. (2018). Aktivitas Promosi Dalam 
Meningkatkan Dana Pihak

Ketiga Pada PT. Bank

Perkreditan Rakyat (BPR)

Batang Kapas Pesisir Selatan.

https://doi.org/10.31227/osf.io/

8dgqn

Kartajaya, Hermawandan Muhammad Syakirsula, 2006. Syariah Marketing, Mizan, Bandung.

Kotler, Philip. 2012 Manajemen Pemasaran: Analisis,

Perencanaan, Implementasi, dan Kontrol. Jilid I. Jakarta: PT Prenhallindo.

1997. Manajemen Pemasaran: Analisis Perencanaan, Implementasi dan kontrol. Jilid II. Jakarta: PT Prenhallindo.

-dan Gary Armstrong. 1997. Prinsip-Prinsip Pemasaran. Jilid I. Alih bahasa: Imam Nurmawan. Jakarta: Erlangga.

Kotler, Philip dan Gary Amstrong, 2001. Prinsip-Prinsip Pemasaran, Jilid 1, Alih Bahasa Damos Sihombing, Erlangga, Jakarta.

Marlius, D. (2016). Pengaruh Bauran

Pemasaran Jasa Terhadap

Minat Nasabah Dalam

Menabung Pada Bank Nagari

Cabang Muaralabuh.

https://doi.org/10.31227/osf.io/ vdqgx
Marlius, D. (2017). Keputusan

Pembelian Berdasarkan Faktor

Psikologis Dan Bauran

Pemasaran Pada PT. Intercom

Mobilindo Padang. Jurnal

Pundi. Volume 1. No. 1. Hal. 57-66.

https://doi.org/10.31575/jp.v1i1

.9

Pramesti, Getut, 2007. Aplikasi SPSS 15.0 dalam Model Linier Statistik. PTElex media Kompotindo, Jakarta.

Santosa, Purbayu Budi danAshari, 2005. Analisis Statistik dengan Microsoft Excel dan SPSS. Penerbit Andi, Yogyakarta.

Singarimbun, Masri. Sofian Efendi, 1995. Metode Penelitian Survey, LP3ES, Jakarta.

Stanton William, 1996, Prinsip Pemasaran, Jilid I, Edisi Ketujuh, Alih Bahasa Yohanes Lamarto, Drs, MBA, MSM, Jakarta : Erlangga.

Sugiyono, 2005. Metode Penelitian Bisnis, Alfabeta, Bandung.

Sulaiman, Wahid, 2002. Jalan Pintas Menguasai SPSS 10. Penerbit Andi, Yogyakarta.

Sunarto,2004. Manajemen Pemasaran. AMUS Yogyakarta \& Aditya Media Yogyakarta, Yogyakarta.

Susanti, F. (2015). Pengaruh Bauran Promosi Terhadap Keputusan Klien Dalam Memilih Radio 
Carano Sebagai Media Promosi Iklan.

https://doi.org/10.31227/osf.io/

b9ws7

Susanti, F. (2014). Pengaruh Tarif

Iklan Terhadap Pendapatan

Pada PT. Radio Swara Carano

Batirai Indah Batusangkar.

https://doi.org/10.31227/osf.io/

dy863

Tim Penyusun, 2005. Buku Pedoman penulisan penulisankarya Ilmiah Fakultas Ekonomi. Penerbit Fakultas Ekonomi UIN Malang, Malang.

Umar, Husein, 2002. Riset Pemasaran dan Perilaku Konsumen. PT. Gramedia Pustaka Utama, Jakarta.

Yazid. 2005. Pemasaran Jasa: Konsep dan Implementas, edisi kedua. Yogyakarta: Ekonisia FE UII. 